\title{
The impact of incentive mechanism and knowledge sharing motivation on the satisfaction of fanpage's members on Facebook in Vietnam
}

\section{Quoc Trung Pham* and Ngoc Kien Phuc Tran}

\author{
School of Industrial Management, \\ Ho Chi Minh City University of Technology (VNU-HCM), \\ 268 Ly Thuong Kiet, D. 10, HCMC, Vietnam \\ Email: pqtrung@hcmut.edu.vn \\ Email: kienphucnc@gmail.com \\ *Corresponding author
}

\begin{abstract}
Social networking is more and more utilised by many companies in marketing, knowledge management, entertainment, and collaboration. However, how to take advantage of social medias to support marketing activities, attracting more customers and encouraging knowledge sharing... is still a difficult question. In addition, the research on knowledge sharing through social networking sites in Vietnam is fairly limited. In this study, the relationship between incentive mechanism, knowledge sharing motivation and the satisfaction of fanpage members on Facebook will be evaluated. Data were collected through a survey in Vietnam. The research model is tested through quantitative analysis on SPSS/AMOS software. The results show that Knowledge sharing motivation and Incentive mechanism have positive impacts on the Satisfaction of fanpage members, while the Incentive mechanism also has a positive impact on Knowledge sharing motivation. Based on this result, suitable Incentive mechanism should be suggested for increasing both members' satisfaction and knowledge sharing motivation.
\end{abstract}

Keywords: incentive mechanism; knowledge sharing motivation; satisfaction; fanpage members; Facebook; Vietnam.

Reference to this paper should be made as follows: Pham, Q.T. and Tran, N.K.P. (2020) 'The impact of incentive mechanism and knowledge sharing motivation on the satisfaction of fanpage's members on Facebook in Vietnam', Int. J. Entertainment Technology and Management, Vol. 1, No. 1, pp.64-79.

Biographical notes: Quoc Trung Pham is a former Vice Dean of School of Industrial Management of Hochiminh city (HCMC) University of Technology, Vietnam. He received his BS and MS in Information Technology from the HCMC University of Natural Science, and $\mathrm{PhD}$ in Economics from the Kyoto University. He has been working in Department of Management Information System since April 2005. His current research focus includes information retrieval system, management information system, decision support system, knowledge management system, e-commerce, e-learning, innovation, etc. He has published and spoken on topics in information technology, MIS, and knowledge management. Until now, he has published four books, two book-chapters, a dozen academic papers on several international journals, and nearly 50 research papers on national and international conferences. 
Ngoc Kien Phuc Tran received his BS in Computer Science and Master's in Management Information System from the HCMC University of Technology (VNU-HCM). He worked at Softtelligence software company since 2014. His current research focus includes management information system, knowledge management, social network, software development, etc.

\section{Introduction}

Recently, the fast development of internet and social networking sites (SNS) leads to the development of digital marketing and the application of SNS in supporting e-commerce activities, such as marketing research, brand-name community, customer engagement through fanpages... Today, marketers realised the benefits of social proof through their fanpage on SNS, and company fanpage become a powerful tool for communicating, knowledge sharing, and collaboration. According to Stavrianea and Kavoura (2015), Facebook is considered one of the most important social media for advertising and marketing. However, how to attract customers to their fanpage and how to keep user satisfaction are challenging questions. There is a need to do more research on this topic for understanding factors affecting the satisfaction of fanpage members on SNS.

In Vietnam, Facebook is considered the top SNS with more than 15 million users (about $40 \%$ of Vietnamese internet users). In 2018, a report of the Global Web Index website showed that most countries in the top 10 list of Facebook users are in Asia, and Vietnam is one of them. According to a forecast of eMarketer, a marketing research company in the USA, the number of Facebook users in Southeast Asia countries is increasing very fast and will be more than US users in a short time. Therefore, research on this topic in Vietnam, a developing country with a high number of Facebook users, is necessary for boosting the development of e-commerce and digital marketing in Vietnam market.

According to Hansemark and Albinsson (2004), customer satisfaction is the overall attitude of customer toward the products or services of the provider. So, in order to increase customer satisfaction, attracting them to join the fanpage of the company, inform them with suitable information/knowledge and make them satisfied is a possible solution. Moreover, company fanpage on SNS is also a powerful tool for reaching potential customers, collecting feedback, and solving complaints. According to Pham and Hara (2009), SNS could be an ideal environment for encouraging knowledge sharing (seeking and offering knowledge/information through interaction) between members. Knowledge sharing on a fanpage is important for the success of any digital marketing plan because it helps to increase interactions and to bring values to all members. So, company fanpage on SNS could be used for supporting knowledge sharing and increasing the satisfaction of members.

According to Chen et al. (2012), incentive mechanism has a positive impact on the satisfaction of community members. In practice, some companies tried to use incentive mechanism for attracting more customers to their fanpage and encouraging interaction between members. Besides, knowledge sharing or interaction of members is very important for the success of any fanpage. A difference from the previous study of Chen et al. (2012), which focuses on virtual communities of practice, this research focuses on brand fanpages on Facebook. Therefore, the relationship between incentive mechanism, 
knowledge sharing motivation, and member satisfaction should be evaluated, especially in the context of Facebook fanpage in a developing country like Vietnam, where there is a lack of research in this topic (Pham, 2017).

Specific research objectives of this research could be summarised as follows:

1 evaluating the relationship between incentive mechanism, knowledge sharing motivation and the satisfaction of fanpage members on Facebook in Vietnam

2 suggesting managerial implications for increasing the satisfaction of fanpage members through incentive mechanism and knowledge sharing motivation for Vietnamese Facebook users.

The rest of the paper is organised as follows: Section 2 offers a literature review on the subject, followed by the presentation of the research model employed, and then a summary of the research process; Section 5 presents the main analysis results, followed by the discussion of the results and policy recommendations, and finally the conclusion of the paper.

\section{Literature review}

\subsection{Main concepts}

\subsubsection{Social network sites}

SNSs or social media are defined as web-based services that enable individuals to:

a create a public or semi-public profile within a bounded system

b link a list of other users with whom they share a connection

c review and track their list of connections and those made by others within the system (Boyd and Ellison, 2008).

SNSs are unique in that they allow social networks to be available to people, and allow users to interact with their social networks (Haythornthwaite, 2005). SNSs have been studied under view of multiple dimensions including usage (Donath and Boyd, 2004); security and privacy (Gross and Acquisti, 2005; Jagatic et al., 2007); social ties (Ellison et al., 2007), cultural differences (Hjorth and Kim, 2005); and natural disaster management (Palen and Vieweg, 2008). Fanpage is a page or group created from an SNS, such as Facebook, Twitter, LinkedIn... It could be controlled by individuals or businesses to support establishing a community of interests, sharing knowledge, or connecting customers of a brand-name. Fanpage is often used by various kinds of enterprises in supporting marketing campaigns, communicating, social interaction, and gaining collective intellectual from its members (Alves et al., 2016; Antoniadis and Charmantzi, 2016). In the scope of this paper, fanpage refers to businesses' fanpage on Facebook SNS.

\subsubsection{Knowledge}

Knowledge is defined as "a justified belief that increases an entity's capacity for effective action" (Alavi and Leidner, 2001). Knowledge is a familiarity, understanding or 
awareness about somebody or something, such as an object, information, descriptions, facts or skills, which is collected through education or experience by learning, discovering or perceiving. It can mention to a theoretical or practical grasp of object or subject. Knowledge could be explicit (as the theoretical understanding of a subject) or implicit (as the practical skill or expertise). Knowledge management is defined as the system or the process in organising and managing knowledge processes, such as identifying gaps of knowledge, acquiring, developing, storing, distributing, sharing and applying the knowledge. The processes of managing knowledge have become to be critical in enhancing the performance of organisations that can either be directed to more creativity or more effectiveness. Knowledge also supplies the foundation for innovation and enhancement in organisations (Verburg and Andriessen, 2011).

\subsubsection{Knowledge sharing}

Knowledge sharing is defined as "the combination of one or both parties seeking knowledge in response to the request, such that one or both parties are affected by the experience" (Ghosh and Scott, 2007). SNS is a good place for social interaction (Pham and Hara, 2009). Via SNSs, individuals can raise their opinion and also show their knowledge just in time. SNSs also enable users to communicate, exchange idea, interact and share their knowledge with other ones in naturally and friendly. SNSs create a good platform for keeping user's engagement by collect the feature, such as pages or groups. The last significant factor would be safe. Users feel safe when they share the idea, knowledge through SNS. The higher level of security, the more information the user can share.

Knowledge sharing motivation refers to the personal need to fulfil individual benefits (Osterloh and Frey, 2000). Psychologists often use a broader concept of motivation, including internal motivation and external motivation (which aims at the group benefit, or social benefit) (Snyder and Cantor, 1998).

\subsection{Foundation theory}

According to Ashley and Tuten (2015), there are two main goals of a brand name's fanpage in engaging customers, including:

1 call for action to users to share content

2 incentivise consumers to submit content (through discounts and coupons).

The first goal relates to knowledge sharing motivation, and the second goal relates to incentive mechanism. This research based on two main theories [social exchange theory (SET) and motivation model] in exploring the relationships between incentive mechanism, knowledge sharing motivation and members' satisfaction on a fanpage. The main ideas of these theories could be summarised as follows:

- $\quad$ SET explains behaviour from a psychological and social viewpoint. In which, cost and benefit analysis are used in any reasonable decision. SET concerns itself with on intrinsic rewards (Blau, 1967). SET presumes that individual behaviours involve benefit maximisation and cost minimisation (Hung et al., 2011). In this research context, knowledge sharing motivation relates to intrinsic concerns of a member in joining an SNS. 
- Motivation model of Porter and Lawla (1975): this model showed that satisfaction is the overall result of many rewards or incentives. The effort or motivation strength depends on the value of reward and the ability to gain that reward. Intrinsic rewards (money, gift) and extrinsic rewards (promotion, working conditions) are the results of finishing tasks well. These rewards and incentives will lead to the satisfaction of employees. In this research, the incentive mechanism is considered an important factor affecting members' satisfaction.

\subsection{Related researches}

Some related researches on this topic could be summarised as follows:

- Harden (2012) showed that trust, risk, benefit, and social influence have impacts on knowledge sharing intention of employees using social media technology in an organisation. In which, people will share their knowledge more if they realise that their knowledge is highly expected and brings more value to the community. The positive impact of social influence and benefit on knowledge sharing intention indicated that Incentive mechanism could play an important role in encouraging knowledge sharing behaviour.

- Chen et al. (2012) conducted a survey in Taiwan to evaluate two hypotheses: (H1) incentive mechanism has a positive impact on knowledge sharing motivation; (H2) incentive mechanism and knowledge sharing motivation have the positive impact on the satisfaction of members on SNS. However, the analysis result could only support H1. Therefore, re-testing these hypotheses in another context could be a possible solution to re-evaluate these relationships.

- Pham and Huynh (2017) showed that the intensity of using SNSs raise the trust and identification dimension of social capital, and these dimensions of social capital have positive effects on e-WOM quality on SNSs. Finally, e-WOM quality impacts positively on Knowledge sharing through SNSs environment in the context of Vietnam. However, the satisfaction of SNS users is not mentioned in this research (although it could be reflected in e-WOM quality).

- Ashley and Tuten (2015) employed a content analysis of the creative strategies present in the social media content shared by a sample of top brands. The results confirmed the importance of frequent updates and incentives for participation. In addition, several creative strategies were associated with customer engagement.

\section{Research model and hypotheses}

\subsection{Suggested research model}

Based on SET and motivation theory of Porter and Lawla (1975), this research focuses on incentive mechanism as a determinant for knowledge sharing and members' satisfaction on a fanpage of SNS. People agree that the success of a fanpage on SNS could be evaluated by the satisfaction of its members because the satisfaction of members will lead 
to customer loyalty and their positive e-WOM, which will attract more customers for the fanpage (Alves et al., 2016). Therefore, the main dependent factor of this research is the satisfaction of fanpage members. Besides, according to Chen et al. (2012), incentive mechanism and knowledge sharing motivation should have positive impacts on the satisfaction of SNS users (but this impact was not confirmed in their result). However, the measurement scales of the above research could be reused for testing these relationships in Vietnam context. In general, some main concepts of the research model could be defined as follows:

- Incentive mechanism: the rewards or benefits that members expect to gain in doing something good, such as: sharing knowledge, helping other members to solve a problem. According to Chen et al. (2012), incentive mechanism includes three main rewards as follows: material reward, social reward, and interactive reward.

- Knowledge sharing motivation: the willingness of members in seeking and offering knowledge or information through interaction on the fanpage. According to Chen et al. (2012), knowledge sharing motivation includes traction motivation, relation motivation, and interest motivation.

- Members'satisfaction: the level of contentment or entertaining feeling of members in joining and interacting on the fanpage.

In summary, the research model could be suggested as in Figure 1.

Figure 1 Suggested research model

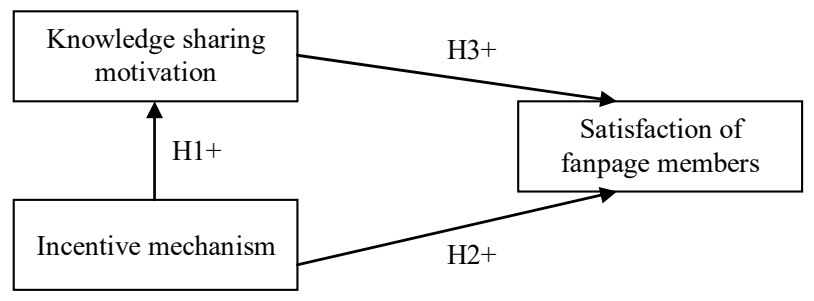

\subsection{Hypotheses}

According to motivation theory of Porter and Lawla (1975), rewards and incentives could have a positive impact on the behaviour and on the satisfaction of employees in an organisation. Besides, Harden (2012) showed that an incentive mechanism is more important in encouraging knowledge sharing behaviour and increasing the satisfaction of the knowledge worker. Ashley and Tuten (2015) also confirmed the impact of incentives on members' satisfaction of social media. Therefore, hypotheses H1 and H2 could be stated as follows:

Hypothesis H1 Incentive mechanism positively related to knowledge sharing motivation of members of fanpage.

Hypothesis H2 Incentive mechanism positively related to satisfaction of members of fanpage. 
According to SET, social interaction or self-fulfilment through knowledge sharing in an online community could be a determinant of individual satisfaction. Besides, previous researches (Chen et al., 2012; Pham and Huynh, 2017) showed that there is a correlation between knowledge sharing and the satisfaction of members on SNS. Therefore, hypothesis $\mathrm{H} 3$ could be stated as follows:

Hypothesis H3 Knowledge sharing motivation positively related to satisfaction of members of fanpage.

\section{Research process}

The research will pass through two stages, pilot test and quantitative method by a survey. A pilot test is firstly executed with 20 respondents to check if they have any difficulty in answering them. Adjusting of scales is activated after this phase. Then, the quantitative method is conducted for testing the reliability of the measurement scales and testing the research hypotheses. Below sections summarise the measurement scale, data collection, and data analysis methods.

\subsection{Measurement scales}

Based on Chen et al. (2012), there are seven broad constructs in this research model which are knowledge sharing motivation (nine items), incentive mechanism (nine items) and satisfaction of members (four items). The scales which are based on English are translated to Vietnamese and major meanings of the scales are keeping. To make it simple, the original multiple dimension scales were combined together into one-dimension scales. After the pilot test, based on the feedback of respondents, some changes in the measurement scales could be summarised as follows: remove 1 item of knowledge sharing motivation, remove 3 items of incentive mechanism, and add 2 more items to satisfaction of members. In general, all 20 items of three factors are used for quantitative research phase.

\subsection{Data collection}

The convenience sampling method is selected for this study. The survey questionnaires are sent to respondents by both ways: paper form (at some business centres and universities in HCMC) and online link (through e-mail and Facebook). According to Hair et al. (2006), the minimum sample size must be five times more than the number of observed variables. Therefore, the minimum sample size for this research is $100(20 \times 5)$. In order to collect enough samples for testing, 250 questionnaires (both online and offline) were sent to target audiences.

\subsection{Data analysis techniques}

After collecting the data, the questionnaires are audited before being processed by the computer Statistic Package for Social Sciences (SPSS) version 20.0. Data analysis is executed by both SPSS and IBM's analysis of moment structures (AMOS) version 21.0 
on windows OS. The structural process of analysing data in this research includes the below stages: descriptive statistics of samples, Cronbach alpha analysis for preliminary assessment of the measurement scales, exploratory factor analysis (EFA) for testing the reliability, confirmatory factor analysis (CFA) for final assessment of the measurement scales and the model, and structural equation modelling for testing model fitness and hypotheses.

\section{Analysis results}

\subsection{Descriptive statistics}

The total of 250 questionnaires has been sent conveniently to respondents in Ho Chi Minh city (both online and offline) during August 2018. In which, 54/70 valid samples collected from the online channel (shared link through e-mail and Facebook), and 149/180 valid samples collected from the offline channel (sent directly at some business centres and universities). In summary, the total valid samples for analysis are 203, which are satisfied with the minimum requirement. Table 1 summarises some characteristics of the samples by gender, age, educational level, and Facebook usage intensive of respondents.

Table 1 Descriptive statistics of samples

\begin{tabular}{llcc}
\hline & & Frequency & Percentage \\
\hline Gender & Male & 115 & 56.7 \\
& Female & 88 & 43.3 \\
& $<25$ & 91 & 44.8 \\
& $25-30$ & 80 & 39.4 \\
& $31-35$ & 29 & 14.3 \\
Educational & $>35$ & 3 & 1.5 \\
level & High school & 5 & 2.5 \\
& College/vocational school & 33 & 16.3 \\
& University & 157 & 77.3 \\
\multirow{3}{*}{ Usage intensive } & Usually & 8 & 3.9 \\
& Post-graduate & 174 & 85.7 \\
& Sometime & 27 & 13.3 \\
& Rarely & 2 & 1.0 \\
\hline
\end{tabular}

In general, the samples' characteristics are suitable for the common features of Facebook users in Vietnam. In which, most people are young $(<30$ years old) and well-educated (university degree or higher), and they spend a lot of time using Facebook (usually).

\subsection{Preliminary assessment of measurement scales}

Table 2 showed that Cronbach alpha coefficients of all factors are reliable (Cronbach alpha > 0.6), and after removing one item in formalisation factor, all item-total 
correlation coefficients are satisfied $(>0.3)$. So, all measurement scales could be used for the next step analysis.

Table 2 Cronbach alpha analysis result

\begin{tabular}{lccc}
\hline Measurement scale & $\begin{array}{c}\text { Cronbach } \\
\text { alpha }\end{array}$ & $\begin{array}{c}\text { Corrected item-total } \\
\text { correlations }\end{array}$ & $\begin{array}{c}\text { \#Item } \\
\text { removed/remained }\end{array}$ \\
\hline Knowledge sharing motivation & 0.780 & $0.357-0.673$ & $3 / 5$ \\
Incentive mechanism & 0.828 & $0.508-0.664$ & $0 / 6$ \\
Satisfaction of fanpage members & 0.855 & $0.606-0.739$ & $0 / 6$ \\
\hline
\end{tabular}

After Cronbach alpha analysis, remained items (17) of the measurement scales are used for EFA. EFA is used to test the measurement scales in the many aspects, such as the unidimensionality, reliability and construct validity, including convergent validity and discriminant validity (Hair et al., 2010). The method principal axis factoring is selected and promax rotation method is used to support the interpretation of factors.

In the EFA test, KMO and Bartlett's test is used for evaluating the scales. After nine times of running EFA, all criteria could be satisfied $(\mathrm{KMO}=0.804>0.5$, sig. $=0.000<0.05$, total extracted variances $=55.221 \%>50 \%$ ) and all factor loading $>0.5$. The remained items (11) of the measurement scales include: knowledge sharing motivation could be separated into two groups: KSM1 (2) and KSM2 (4), incentive mechanism (3), and members' satisfaction (2). The separation of knowledge sharing motivation is suitable with the original scale because KSM1 relates to traction motivation and KSM2 relates to relation and interest motivation as mentioned in Chen et al. (2012).

\subsection{The revised model}

Based on previous results, the research model must be revised and summarised in Figure 2. Therefore, hypotheses must be re-stated as follows.

Hypothesis H1a Incentive mechanism positively related to knowledge sharing motivation 1 (traction motivation) of members of fanpage.

Hypothesis H1b Incentive mechanism positively related to knowledge sharing motivation 2 (relation and interest motivation) of members of fanpage.

Hypothesis H2 Incentive mechanism positively related to satisfaction of members of fanpage.

Hypothesis H3a Knowledge sharing motivation 1 (traction motivation) positively related to satisfaction of members of fanpage.

Hypothesis H3b Knowledge sharing motivation 2 (relation and interest motivation) positively related to satisfaction of members of fanpage. 
Figure 2 The revised research model

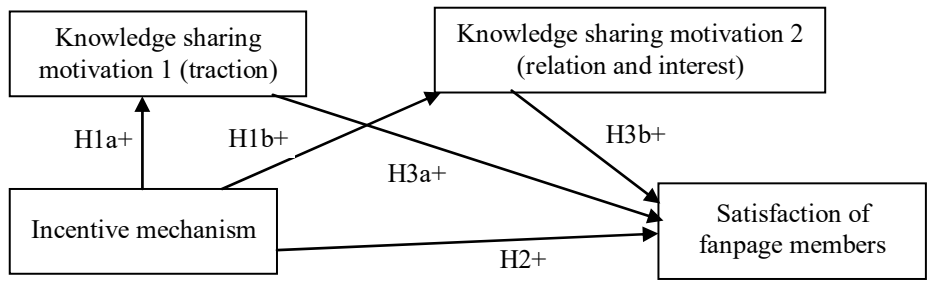

\subsection{Final assessment of the measurement scales using CFA}

After the EFA phase, all remained items are used for CFA with the support of AMOS software. The purpose of this step is to check whether the model is fit with the sample data or not. Some criteria to be checked include chi-square/df $<3$, goodness of fit index (GFI), Tucker Lewis index (TLI), and comparative fit index (CFI) $>=0.9$, and root mean squared error of approximation (RMSEA) < 0.8 (Nguyen and Nguyen, 2009). The result of CFA could be summarised in Figure 3. Based on this result, chi-square/df $=1.107$ $(<3), \mathrm{CFI}=0.976, \mathrm{GFI}=0.961$, and TLI $=0.965(>0.9)$, and $\mathrm{RMSEA}=0.023(<0.8)$. Therefore, the model is fit with the market data.

Figure 3 Standardised CFA results (see online version for colours)

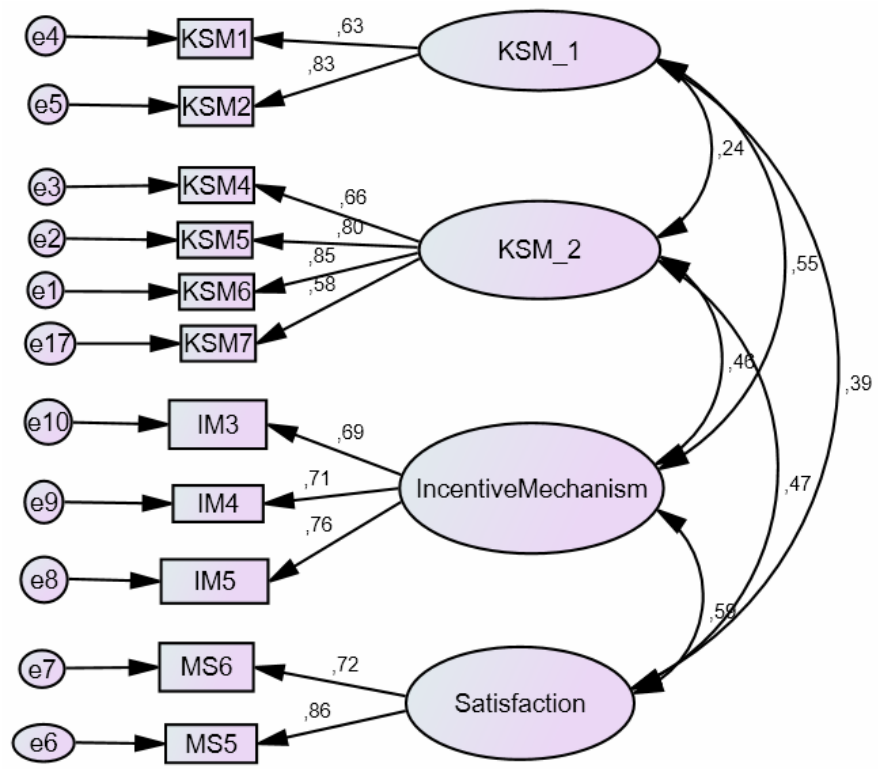

Notes: Chi-square $=42.080 ; \mathrm{df}=38 ; \mathrm{P}=0.299 ;$ chi-square $/ \mathrm{df}=1.107 ; \mathrm{GFI}=0.962$;

$\mathrm{TLI}=0.965 ; \mathrm{CFI}=0.976 ;$ RMSEA $=0.023$. 
Besides, all of the composite reliability (CR) scores are greater than 0.60 , and all of the average variance extracted (AVE) scores are greater than 0.50 . So, they are suitable for the requirements (Nguyen and Nguyen, 2009).

\subsection{Test model and hypothesis using SEM}

With the support of AMOS software, the above CFA model is turned into a SEM model for testing the hypothesis and evaluating the impacts of causal relationships. The result of SEM analysis could be summarised in Figure 4.

Figure 4 Standardised SEM analysis results (see online version for colours)

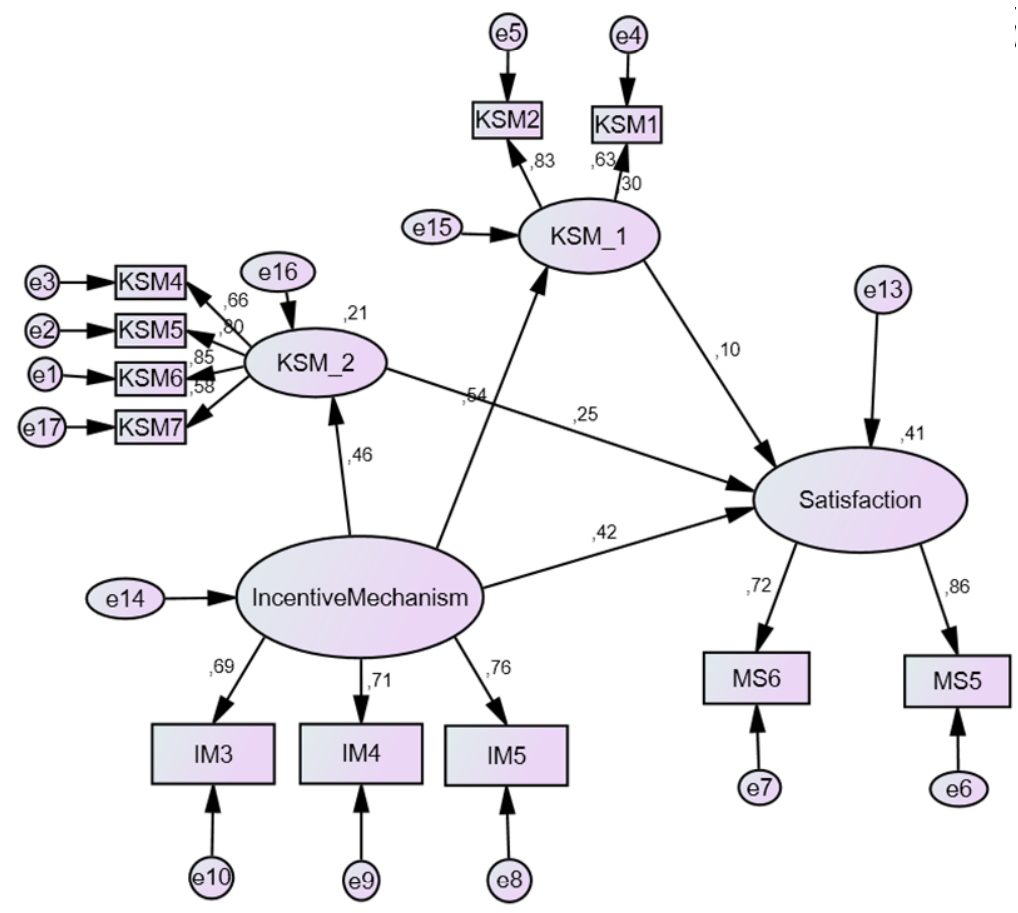

Notes: Chi-square $=42.091 ; \mathrm{df}=39 ; \mathrm{P}=0.339 ;$ chi-square $/ \mathrm{df}=1.079 ; \mathrm{GFI}=0.962$;

$\mathrm{TLI}=0.974 ; \mathrm{CFI}=0.982 ; \mathrm{RMSEA}=0.020$.

Table 3 Summary of hypothesis test results

\begin{tabular}{|c|c|c|c|c|c|c|c|}
\hline & & & Estimate & S.E. & C.R. & $P$ & Result \\
\hline $\mathrm{H} 1 \mathrm{~b}$ & KSM_2 & $<---$ Incentive mechanism & 0.462 & 0.104 & 5.033 & $* * *$ & Accepted \\
\hline H1a & KSM_1 & $<---$ Incentive mechanism & 0.544 & 0.133 & 4.187 & $* * *$ & Accepted \\
\hline $\mathrm{H} 2$ & Satisfaction & $<---$ Incentive mechanism & 0.422 & 0.144 & 3.357 & $* * *$ & Accepted \\
\hline $\mathrm{H} 3 \mathrm{a}$ & Satisfaction & $<---\quad$ KSM_1 & 0.103 & 0.120 & 0.960 & 0.337 & Rejected \\
\hline $\mathrm{H} 3 \mathrm{~b}$ & Satisfaction & $<---\quad$ KSM_2 & 0.246 & 0.094 & 2.647 & 0.008 & Accepted \\
\hline
\end{tabular}

Note: $* * *<0.001$ 
The SEM analysis result showed that all criteria were satisfied (chi-square/df $<3$, GFI, TLI, and CFI $>=0.9$, and RMSEA $<0.8$ ). Therefore, the model could be used for testing the hypothesis. According to this result, the summary of hypotheses test could be presented as Table 3.

\section{Discussion of the results}

\subsection{Discussion}

Table 4 compares the difference between the previous results of Chen et al. (2012) and this analysis result.

Table 4 Comparison of this result and the previous result of Chen et al. (2012)

\begin{tabular}{lcc}
\hline & Chen et al. (2012) & This research \\
\hline H1: IM $->$ KSM & Accepted & Accepted H1a (0.544), accepted H1b (0.462) \\
H2: IM $->$ MS & Not confirmed & Accepted (0.523) \\
H3: KSM $>$ MS & Not confirmed & Rejected H3a, accepted H3b $(0.246)$ \\
\hline
\end{tabular}

Based on this result, the incentive mechanism strongly influences on members' satisfaction and knowledge sharing motivation also has a positive impact on members' satisfaction (but not as strong as the impact of incentive mechanism). So, the incentive mechanism plays an important role in raising both members' satisfaction and knowledge sharing motivation. However, Chen et al. (2012) focused on virtual communities of practice, which were a little bit different from fanpages. Although both environments try to attract members by increasing their satisfaction, the main goals of these environments are different. While virtual communities of practice try to encourage knowledge sharing, the main goal of fanpage is to support sale and marketing activities.

Moreover, this result could be used as evidence to persuade business managers to invest more on the organisational social network as a mean for increasing members' satisfaction and encouraging knowledge sharing motivation. In general, the social network could be considered an ideal solution for knowledge management and marketing as confirmed in previous studies (Alves et al., 2016; Pham, 2017). The social network should be used to connect customers and employees, to co-create business values, to accumulate collective knowledge, and to support communication and collaboration between members. Based on this result, in order to ensure the success of the organisational social network, some suitable incentive mechanisms must be established and put in practice.

According to Kietzmann et al. (2011), there are seven main functions of any social media, including identity, conversations, sharing, presence, relationships, reputation, and groups. Therefore, extending the scope of function of social media used should also help to increase members' satisfaction and to improve the effectiveness of digital marketing campaigns. 


\subsection{Managerial implications}

In general, this research confirmed the important role of company fanpage in marketing and knowledge management activities. In which, a suitable incentive mechanism on company fanpage will help to increase both members' satisfaction and knowledge sharing motivation. Besides, in encouraging knowledge sharing motivation, this result showed that relation and interest motivation significantly impacted on members' satisfaction, but traction motivation had no impact. Based on this result, some managerial implications could be suggested as follows:

- Incentive mechanism has the highest impact on members' satisfaction (beta $=0.523$ ) and it has an indirect impact on members' satisfaction through knowledge sharing motivation. Therefore, the incentive mechanism must be used frequently to encourage knowledge sharing motivation and to increase members' satisfaction. A combination of physical and spiritual incentive methods should be applied. For example, a real award (gift/voucher/money) for a contest organised on fanpage, an increase in members' status, a certification for some contribution... could help to make users happy and to encourage them to share knowledge more.

- Knowledge sharing motivation (relation and interest motivation) has a positive impact on members' satisfaction (beta $=0.246$ ), so fanpage admin should interact with users more and encourage them to ask or answer questions on the fanpage. Relation and interest motivation should be used to encourage knowledge sharing motivation between members, such as: focusing on social benefits, building a reputation, supporting collaboration... Besides, online survey could also be used for collecting feedback from members to know how to improve the features of the fanpage to boost knowledge sharing motivation. Recognition of members' status and suitable awards for members of high-quality contributions (posts/comments/ sharing...) could be a possible solution for increasing knowledge sharing behaviour and improving the overall quality of fanpage communication.

Moreover, fanpage managers should focus on entertaining activities and creative contents to attract more participants and to improve their marketing effectiveness (Antoniadis et al., 2017). A digital marketing plan focusing on user-generated content will help to increase co-creation value and business performance.

\section{Conclusions and recommendations}

In general, social commerce becomes more and more important in the digital world, and fanpage is used frequently by many organisations for attracting customers and supporting their business goals. This research tried to explore the relationship between incentive mechanism, knowledge sharing motivation, and members' satisfaction in the context of company fanpage in Vietnam. From a survey of 203 valid respondents in Ho Chi Minh city, the research model has been tested. In which, incentive mechanism has positive impacts on members' satisfaction, and on knowledge sharing motivation, and knowledge sharing motivation has a positive impact on members' satisfaction.

Based on this result, an incentive mechanism could be considered a powerful tool for supporting both benefits, including knowledge sharing motivation (long-term benefits of 
fanpage) and members' satisfaction (short-term benefits of fanpage). Therefore, the fanpage admin and digital marketing department of e-businesses should pay more attention to find suitable incentive mechanism for their fanpage in order to gain both long-term and short-term benefits. Besides, regarding knowledge sharing motivation, companies should pay more attention to increase relation and interest motivation rather than traction motivation because of the former impacts significantly on member's satisfaction on company fanpage.

However, there are still some limitations of this research, including:

1 a small sample size and convenient sampling method could reduce the possibility to generalise the result

2 the use of first-order constructs rather than second order constructs as in the original research may reduce the ability to measure the overall impact of the model

3 some other factors impacting on members' satisfaction were not mentioned in the research model, such as service quality, fanpage design, psychological and technological aspects.

Therefore, some directions for the future research include:

1 increase the sample size and extend the research scope to other areas in Vietnam or to cover other SNSs

2 use the second order constructs for testing the SEM model

3 add other factors to the research model to test their impacts on fanpage members' satisfaction.

\section{References}

Alavi, M. and Leidner, D.E. (2001) 'Review: knowledge management and knowledge management systems: conceptual foundations and research issues', MIS Quarterly, Vol. 25, No. 1, pp.107-136.

Alves, H., Fernandes, C. and Raposo, M. (2016) 'Social media marketing: a literature review and implications', Psychology and Marketing, Vol. 33, No. 12, pp.1029-1038.

Antoniadis, I. and Charmantzi, A. (2016) 'Social network analysis and social capital in marketing: theory and practical implementation', International Journal of Technology Marketing, Vol. 11, No. 3, pp.344-359.

Antoniadis, I., Koukoulis, I. and Serdaris, P. (2017) 'Social networking sites' usage in a period of crisis. A segmentation analysis of Greek college students', Strategic Innovative Marketing, pp.73-79.

Ashley, C. and Tuten, T. (2015) 'Creative strategies in social media marketing: an exploratory study of branded social content and consumer engagement', Psychology and Marketing, Vol. 32, No. 1, pp.15-27.

Blau, P.M. (1967) Exchange and Power in Social Life, Wiley, New York.

Boyd, D.M. and Ellison, N.B. (2008) 'Social network sites: definition, history, and scholarship', Journal of Computer-Mediated Communication, Vol. 13, No. 1, pp.210-230.

Chen, C.S., Chang, S.F. and Liu, C.H. (2012) 'Understanding knowledge sharing motivation, incentive mechanisms, and satisfaction virtual communities', Social Behavior \& Personality, Vol. 40, No. 4, pp.639-648. 
Donath, J. and Boyd, D. (2004) 'Public displays of connection', BT Technology Journal, Vol. 22, No. 4, pp.71-82.

Ellison, N., Steinfield, C. and Lampe, C. (2007) 'The benefits of Facebook 'friends': exploring the relationship between college students' use of online social networks and social capital', Journal of Computer-Mediated Communication, Vol. 12, No. 3, pp.1143-1168.

Ghosh, B. and Scott, J.E. (2007) 'Social capital in knowledge-based business process outsourcing', Proceedings of the 13th Americas Conference on Information Systems, Keystone, pp.1-12.

Global Web Index (2018) GWI Social Summary Report [online] https://www.globalwebindex.com/ reports (accessed 3 December 2018).

Gross, R. and Acquisti, A. (2005) 'Information revelation and privacy in online social networks', Proceedings of 2005 ACM Workshop on Privacy in the Electronic Society, Alexandria, pp.71-80.

Hair, J.F., Anderson, R.E., Tatham, R.L. and Black, W.C. (2006) Multivariate Data Analysis, Prentice-Hall, New Jersey.

Hair, J.F., Black, W.C., Babin, B.J. and Anderson, R.E. (2010) Multivariate Data Analysis, Upper Saddle River, Prentice-Hall, New Jersey.

Hansemark, O.C. and Albinsson, M. (2004) 'Customer satisfaction and retention: the experiences of individual employees', Managing Service Quality: An International Journal, Vol. 14, No. 1, pp.40-57.

Harden, G. (2012) Knowledge Sharing in the Workplace: a Social Networking Site Assessment, University of North Texas.

Haythornthwaite, C. (2005) 'Social networks and internet connectivity effects', Information Communication and Society, Vol. 8, No. 2, pp.125-147.

Hjorth, L. and Kim, H. (2005) 'Being there and being here: Gendered customizing of mobile 3G practices through a case study in Seoul', Convergence, Vol. 11, No. 2, pp.49-55.

Hung, S.Y., Durcikova, A., Lai, H.M. and Lin, W.M. (2011) 'The influence of intrinsic and extrinsic motivation on individuals' knowledge sharing behavior', International Journal of Human-Computer Studies, Vol. 69, No. 6, pp.415-427 [online] doi:https://doi.org/10.1016/ j.ijhcs.2011.02.004.

Jagatic, T., Johnson, N., Jakobsson, M. and Menczer, F. (2007) 'Social phishing', Communications of the $A C M$, Vol. 5, No. 10, pp.94-100.

Kietzmann, J.H., Hermkens, K., McCarthy, I.P. and Silvestre, B.S. (2011) 'Social media? Get serious! Understanding the functional building blocks of social media', Business Horizons, Vol. 54, No. 3, pp.241-251.

Nguyen, D.T. and Nguyen, T.M.T. (2009) Scientific Research in Business Administration, Statistic Publishing House, Ha Noi.

Osterloh M. and Frey B. (2000) 'Motivation, knowledge transfer, and organization forms', Organization Science, Vol. 11, No. 5, pp.538-550.

Palen, L. and Vieweg, S. (2008) 'The emergence of online widescale interaction in unexpected events: assistance, alliance \& retreat', in Proceedings of the 2008 ACM Conference on Computer Supported Cooperative Work, ACM, pp.117-126.

Pham, Q.T. (2017) A Knowledge Management Approach for Ensuring the Success of IT Industries in Vietnam, Nova Science Publishers, New York.

Pham, Q.T. and Hara, Y. (2009) 'Combination of two KM strategies by Web 2.0', in Karagiannis, D. and Jin, Z. (Eds.): Knowledge Science, Engineering and Management, KSEM, Lecture Notes in Computer Science, Vol. 5914, Springer, Berlin, Heidelberg.

Pham, Q.T. and Huynh, V.K. (2017) 'The impacts of using SNSs on e-WOM and knowledge sharing through social capital: an empirical study in Vietnam', in Gervasi, O. et al. (Eds.): Computational Science and Its Applications - ICCSA 2017, ICCSA, Lecture Notes in Computer Science, Vol. 10409, Springer, Cham. 
Porter, L.W. and Lawler, E.E. (1975) Behavior in Organization, McGraw-Hill International, New York.

Snyder, M. and Cantor, N. (1998) 'Understanding personality and social behavior: a functionalist strategy', in Gilbert, D.T., Fiske, S.T. and Lindzey, G. (Eds.): The Handbook of Social Psychology, pp.635-679, McGraw-Hill, New York, NY, US.

Stavrianea, A. and Kavoura, A. (2015) 'Social media's and online user-generated content's role in services advertising', in AIP Conference Proceedings, Vol. 1644, No. 1, pp.318-324.

Verburg, R. and Andriessen, E. (2011) 'A typology of knowledge sharing networks in practice', Knowledge and Process Management, Vol. 18, No. 1, pp.34-44.

\section{Appendix}

Table A1 Measurement scales

Knowledge sharing motivation (KSM)

KSM1 - You expect to receive a monetary award in sharing your knowledge on the fanpage.

KSM2 - You expect to receive gifts or vouchers in sharing your knowledge on the fanpage.

KSM3 - You expect to get the answers for your own questions when answering questions of other members on the fanpage.

KSM4 - Sharing your knowledge on the fanpage will help you to get acquainted with other members.

KSM5 - Sharing your knowledge on the fanpage will strengthen the relationship between you and other members in the fanpage community.

KSM6 - Knowledge sharing will help to extend the linkage between members in the fanpage community.

KSM7 - Knowledge sharing will lead to the collaboration between members in the future.

KSM8 - Knowledge sharing will help fanpage members to work effectively.

Incentive mechanism (IM)

IM1 - The fanpage has a proper scoring system in its competitions.

IM2 - The fanpage members will get scores for their interaction (posting, voting, like, comment...).

IM3 - The fanpage displayed the list of active members on its main page.

IM4 - The fanpage recommended the users' posts with high quality.

IM5 - The fanpage give awards or certificates for users with a high contribution on their profiles.

IM6 - The fanpage promoted the outstanding members to be admin of the fanpage.

Members' satisfaction (MS)

MS1 - The fanpage you joined is very useful.

MS2 - You enjoy various activities (competition, off-line events, Q\&A...) on the fanpage.

MS3 - You feel satisfied with the current services/activities of the fanpage.

MS4 - You feel entertained and fun in joining this fanpage.

MS5 - You feel satisfied with the company brand-name shown on the fanpage.

MS6 - You feel satisfied with the product of this company fanpage. 